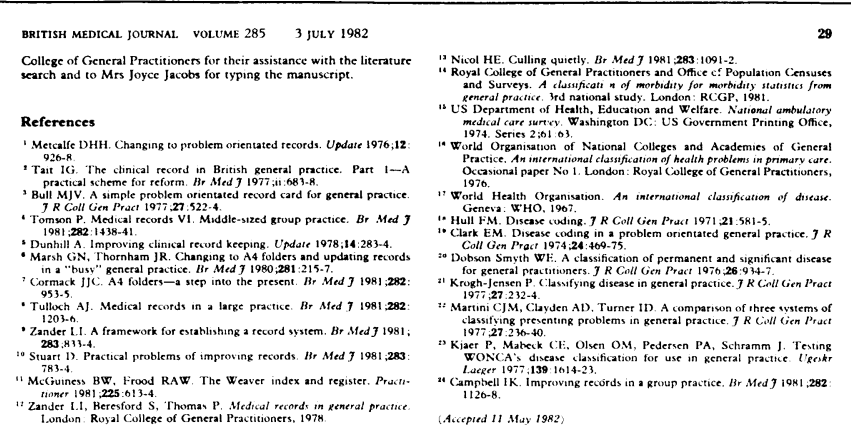

The Course Organiser

\section{Day-release courses in the West Midlands}

$G$ W THORPE

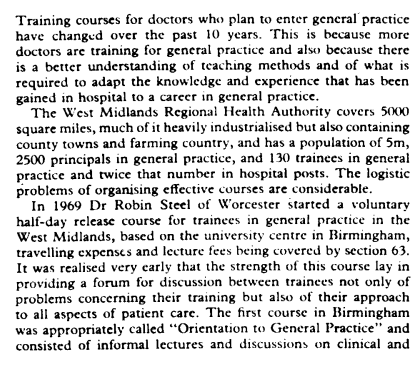

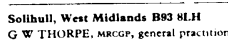

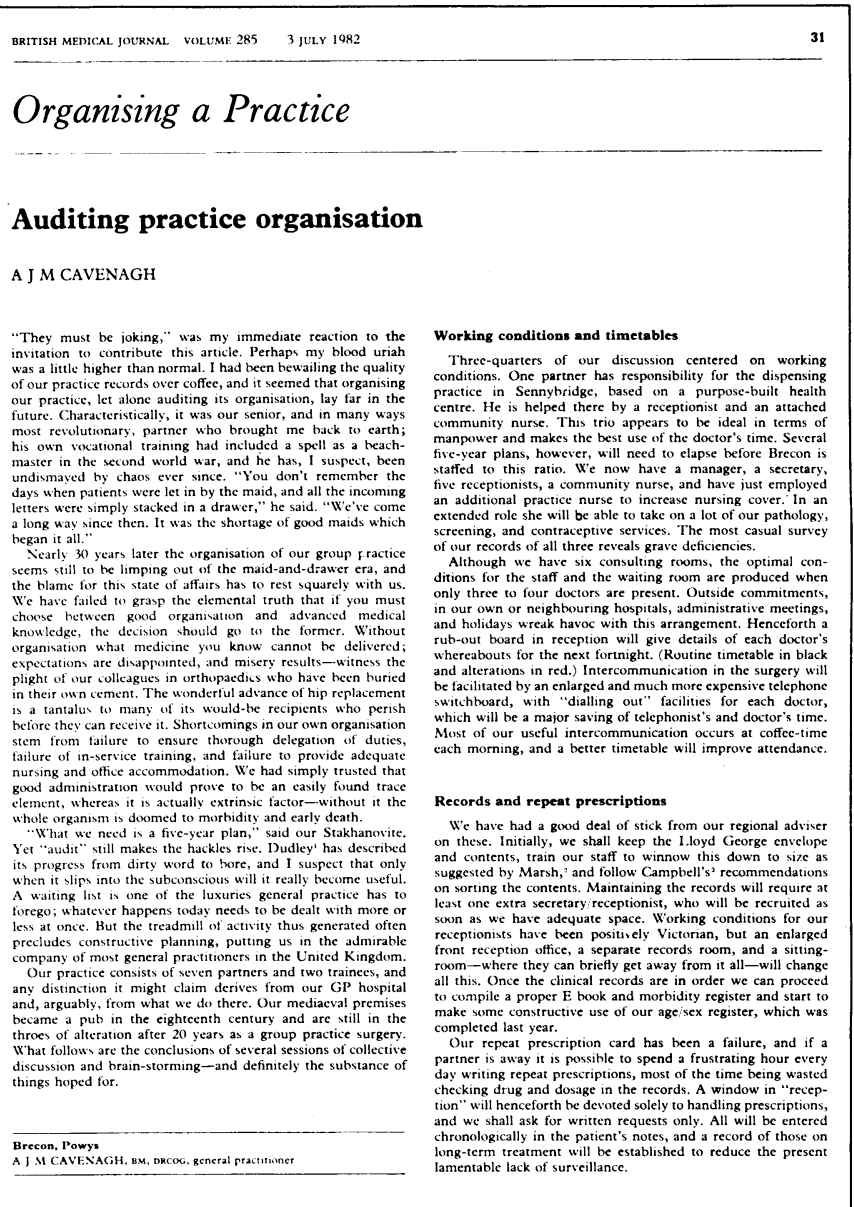

32

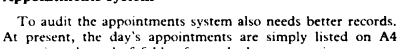

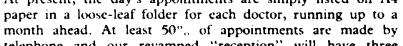

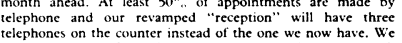

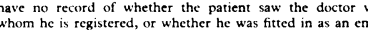

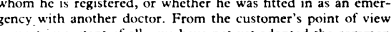

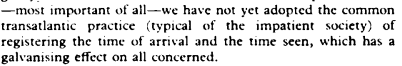

Referrals, library, and training

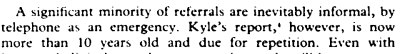

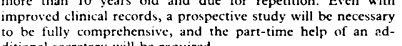
ditional sccretary will be required.
Two members of the practicic constute the library sub-
commitrec, tharged with the task of updating the library and

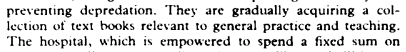

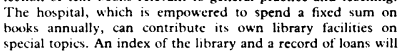

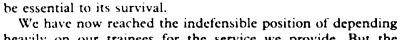

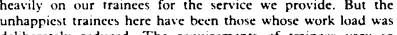

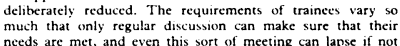

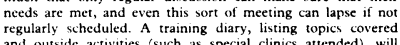

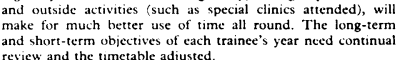
Medical students

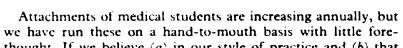

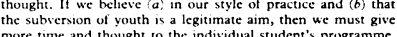

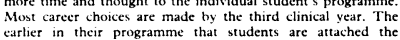

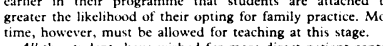

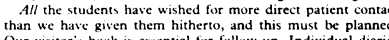

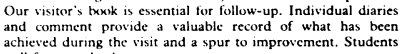
Building and tinance

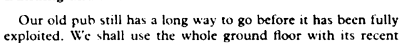

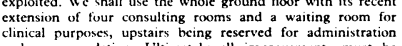

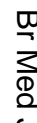

$\stackrel{\frac{2}{c}}{3}$

$\bar{\Xi}$

ग

ma

ज

రृ

$\frac{\bar{\sigma}}{\bar{\sigma}}$

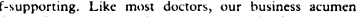

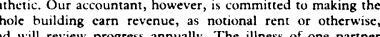

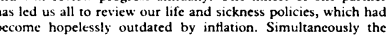

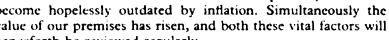

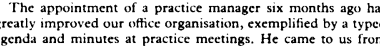

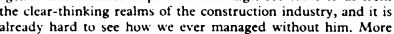
and morc problems arc simply piled on to his wiling sthoulders.
Though the most modest of men, he confessed recenly that

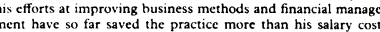

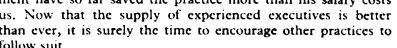

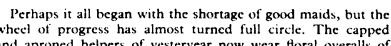

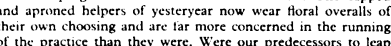

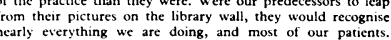

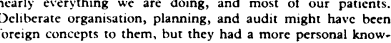

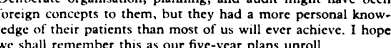

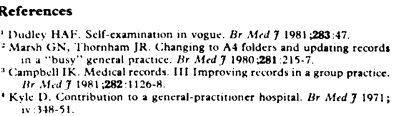

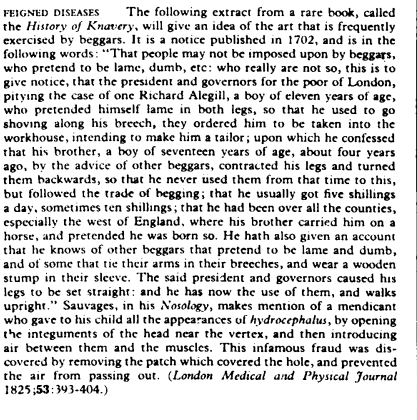

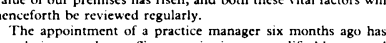

